\title{
Labyrinthitis and Labyrinthitis Ossificans - A case report and review of the literature
}

\author{
Pritee Taxak $^{1 *}$, Chithra Ram ${ }^{1}$ \\ 1. Department of Radiology, University of Louisville Hospital, Kentucky, USA \\ * Correspondence: Dr. Pritee Taxak, Department of Radiology, University of Louisville Hospital, 530 South Jackson Street, CCB-C07, \\ Louisville, Kentucky 40202, USA \\ $(\triangle$ pritee.taxak@louisville.edu) \\ Radiology Case. 2020 May; 14(5):1-6 :: $\quad$ DOI: $10.3941 /$ jrcr.v14i5.3706

\begin{abstract}
Labyrinthitis most commonly results from an infectious and less commonly temporal bone trauma, hemorrhage, or tumor. This inflammation (regardless of the etiology) disrupts the transmission of sensory information from the ear to the brain. Labyrinthitis ossificans is the pathological ossification of the membranous labyrinthine spaces in response to an insult to the inner ear involving membranous labyrinth or the endosteum of the otic capsule. Herein, we present a case of a 67 -year-old female with progressive bilateral sensorineural hearing loss and positional vertigo.
\end{abstract} \\ from an inflammatory process of the inner ear, but it can be associated with
}

\section{CASE REPORT}

\section{CASE REPORT}

A 67-year-old female, who had a history of Diabetes mellites type 2 presented with progressive bilateral sensorineural hearing loss (left much worse than right) and positional vertigo. The patient developed right ear infection with sudden severe right sided hearing loss with no reported history of meningitis. Multiple studies including Audiograms, tympanograms and Electronystagmography were performed along with imaging to aid with diagnosis.

The 64 slice Siemens CT demonstrated varying degrees of ossification with sclerosis, involving the cochlea, semicircular canals and vestibule on the left side. The Siemens 1.5 Tesla MRI images demonstrated loss of normal fluid signal in the left inner ear and post contrast enhancement of the labyrinth involving right inner ear. These findings were compatible with LO on the left and labyrinthitis on the right side. The dense ossification in the left cochlea was contraindication for implant and hence, the patient tried intratympanic dexamethasone injection on the right side, with little symptom relief.

The patient was treated with cochlear implantation on the right side.

\section{DISCUSSION}

\section{Etiology \& Demographics:}

Labyrinthitis: The most common cause of Labyrinthitis are the infections of the inner ear, which are usually viral or bacterial. Other less common causes that result in labyrinthitis include inflammatory process of the inner ear, temporal bone trauma, hemorrhage and tumors. In most cases, labyrinthitis is caused by a viral infection. Labyrinthitis often follows common illnesses such as a cold or flu. The other most 
common viruses known to cause labyrinthitis include herpes, measles, mumps and rubella to name a few. The bacterial infections of the middle ear which are fairly common in children can spread to inner ear and cause labyrinthitis. In chronic middle ear infection, the bacteria may enter the inner ear through the oval or round windows, through the bone or as a result of injury to the head or ear. The labyrinth injury as a sequel to infection and/or otic capsule trauma with subsequent ossification can result in hearing loss. The infections can reach inner ear through blood flow (hematogenic), through middle ear (tympanogenic) or through meninges (meningogenic) $[1,3,5]$. Ossification is typically unilateral but can be bilateral and can be found 3-4 months after bacterial meningitis and/or trauma. Labyrinthitis can occurs in all age groups but is more common in 30 to 50-year old. Females are slightly more susceptible than males, at a ratio of 1.5:1.

\section{Clinical Presentation:}

The patients usually present with irreversible hearing loss, vertigo and vomiting. The symptoms are often precipitated by sudden movements. Although the early stages are mild, they can be associated with dizziness, difficulties with balance, visual disturbance or hearing impairment. The patients can also experience dizziness of any degree either during acute infectious condition or during disease development.

Our patient had a prior history of sensorineural hearing loss on the left side secondary to Labyrinthitis Ossificans. During current presentation, the patient presented with positional vertigo and right-sided hearing loss. No history of meningitis.

\section{Pathophysiology:}

Regardless of etiology, LO pathogenesis involves acute inflammation as an initial stage, followed by a stage characterized by proliferation of fibroblasts and fibrosis which results in labyrinth ossification. In cases of infection, bacteria or virus are present in the peri-lymphatic spaces causing acute inflammation. Post-traumatic labyrinthitis develops from subsequent inflammation, which can be usually seen in the setting of otic capsule trauma caused by temporal bone fractures and/or tumors[1,3,5].

\section{Imaging Findings:}

CT: CT shows high-density bone deposition within the membranous labyrinth. LO may present with sclerosis, irregularities or obliteration of the cochlea, semicircular canals or vestibule with different degrees of involvement. CT is specific but has a lower sensitivity with respect to MRI.

It has a spectrum with:

- mild LO: hazy increase in density within fluid spaces of the membranous labyrinth.

- moderate LO: Intermittent ossifications within fluid spaces of the membranous labyrinth.

- severe LO: membranous labyrinth is completely obliterated by bone replacing fluid spaces.
MRI: Loss of normal fluid signal in the inner ear.

T2: Ossifications may show low-intensity foci within high signal fluid of inner ear.

Post Contrast: Enhancement on MRI is seen in the early acute/subacute stage when there is inflammation-related hypervascularity.

\section{Treatment \& Prognosis:}

Currently there are a range of treatment options for labyrinthitis ossificans. Cochlear implantation is an effective treatment for sensorineural hearing loss. However, ossification of the membranous labyrinth can make electrode implantation difficult, which in turn may either complicate or preclude cochlear implantation. A cochlear implant is an electronic device that can partially restore hearing. It can be an option for people with severe hearing loss from inner-ear damage and for those with limited benefit from hearing aids[3,4,5,6].

\section{Differential Diagnosis:}

The differential diagnosis includes cochlear aplasia or labyrinthine aplasia. In labyrinthitis ossificans, the shape/contour of the labyrinth is preserved. However, labyrinthine aplasia is characterized by bilateral absence of differentiated inner ear structures. Another differential includes otosclerosis, which is an osteodystrophy of the Otic capsule, which involves the oval window and stapes in "fenestral" subtype and extends to involve cochlea in "retrofenestral" subtype. This results in conductive, mixed or sensorineural hearing loss, often in 2 nd to 4 th decades of life. While otosclerosis results in demineralization/hypodensity of otic capsule; LO shows ossification of the membranous labyrinth $[2,4]$.

\section{TEACHING POINT}

Labyrinthitis ossificans is ossification of the inner ear structures. Patients present with profound irreversible hearing loss. LO can be diagnosed definitively on imaging with CT, which shows ossification of the membranous labyrinth, and can be suggested on MRI, which shows loss of normal fluid signal in the inner ear. In the acute/subacute stage of labyrinthitis without ossification, MRI shows enhancement of the membranous labyrinth. Imaging findings are important for treatment guidance (selection of appropriate patients for cochlear implantation) and for prognostication.

\section{REFERENCES}

1. Swartz JD, Mandell DM, Faerber EN, Popky GL, Ardito JM, Steinberg SB, Rojer CL. Labyrinthine ossification: etiologies and CT findings. Radiology. 1985 Nov;157(2):3958. PMID: 3931172

2. Booth TN, Roland P, Kutz JW, Lee K, Isaacson B. Highresolution 3-D T2-weighted imaging in the diagnosis of labyrinthitis ossificans: emphasis on subtle cochlear 
involvement. Pediatr Radiol. 2013; 43(12):1584-1590. PMID: 23843131

3. Mattiola LR, Makowiecky M, Guimarães de Salles CE, Cardoso MP, Cahali S. Labyrinthitis Ossificans. Report of One Case and Literature Review. International archives of Otorhinolaryngology. 2008. Vol 12. Num 2-Apr/June. Available at: arquivosdeorl.org.br/additional/acervo_eng.asp? $\mathrm{id}=530$. Accessed on May 20,2019.

4. Cody Larson, MD; Scott A. Jorgensen, MD; Alexander J. Towbin, MD; and Richard Towbin, MD. Labyrinthine ossificans. Applied Radiology. Online Oct 2016. Available at: https://www.appliedradiology.com/communities/breastimaging/labyrinthine-ossificans. Accessed on May 30,2019.
5. Becker TS, Eisenberg LS, Luxford WM, House WF. Labyrinthine ossification secondary to childhood bacterial meningitis: implications for cochlear implant surgery. AJNR Am J Neuroradiol. 1984; 5(6):739-741. PMID: 6437175

6. Harnsberger HR, Dart DJ, Parkin JL, Smoker WR, Osborn AG. Cochlear implant candidates: assessment with CT and MR imaging. Europe PMC Radiology. 30 June, 1987. 164(1):53-57. PMID: 3108956

\section{FIGURES}
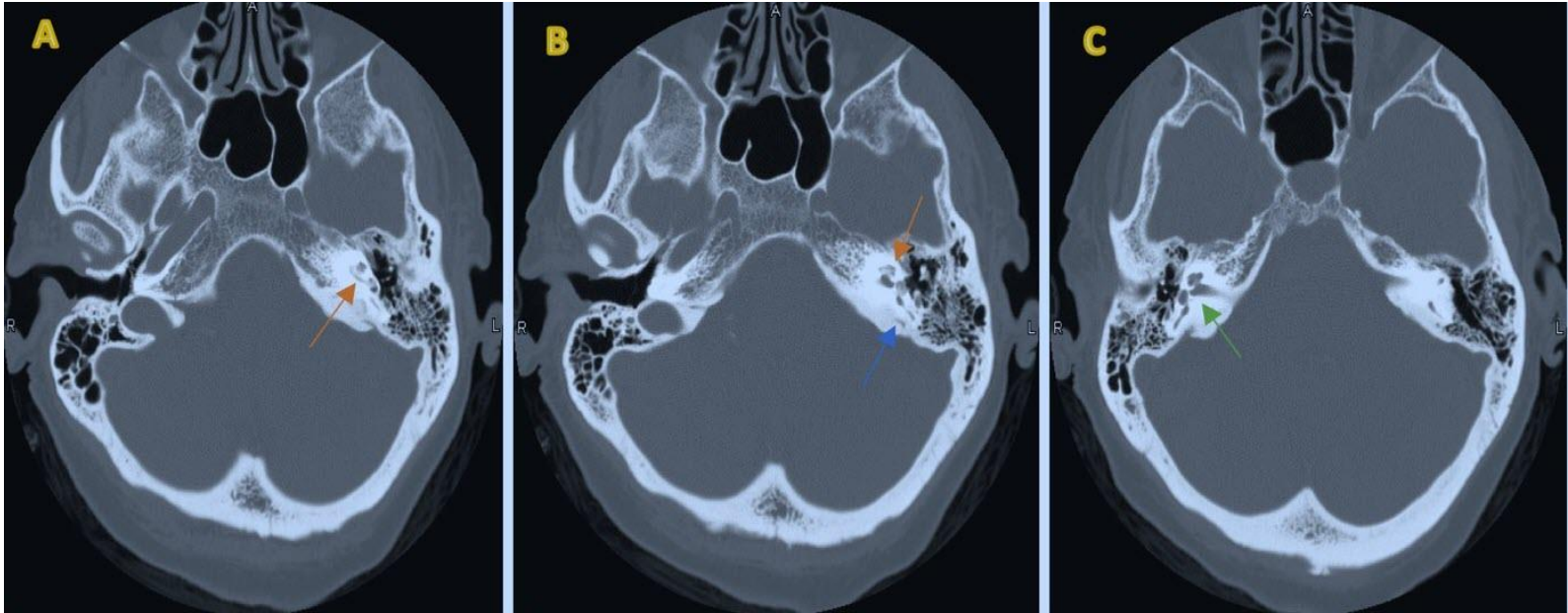

Figure 1: 67 year old female with a history of relapsing polychondritis in bilateral external ears and Diabetes mellitus Type -2 presented with progressive bilateral sensorineural hearing loss (left much worse than right) and positional vertigo.

Findings: Axial (A, B and C) images of temporal bones. Image A demonstrates high-density bone deposition within the left cochlea (orange arrow). Image B demonstrates high-density bone deposition within the left cochlea (orange arrow) and left vestibule (blue arrow) of the membranous labyrinth. These findings are consistent with labyrinthitis ossificans. Image $\mathrm{C}$ demonstrates a normal appearing right membranous labyrinth (green arrow).

Technique: Helically acquired, non-contrast 64 slice Siemens CT of bilateral temporal bones with $0.6 \mathrm{~mm}$ thin images in axial plane. FOV is $15.4 \mathrm{~cm}$. 


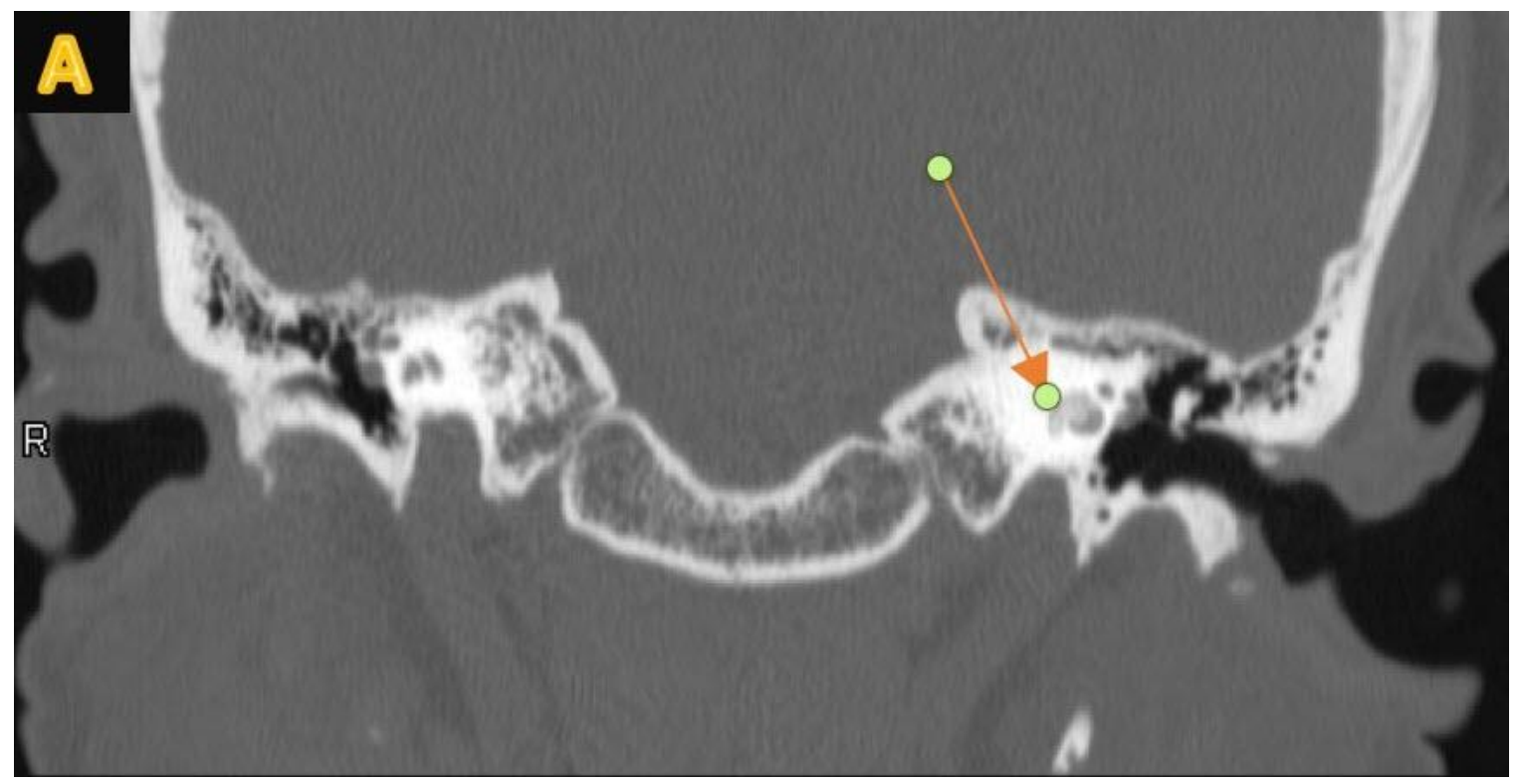

Figure 2: 67 year old female with a history of relapsing polychondritis in bilateral external ears and DM-2 presented with progressive bilateral sensorineural hearing loss (left much worse than right) and positional vertigo[3,6].

Findings: Coronal reconstructed images of temporal bones (Fig. A). Image A demonstrates high-density bone deposition within the left cochlea (orange arrow). The findings are consistent with left labyrinthitis ossificans. The right membranous labyrinth is unremarkable.

Technique: Helically acquired, non-contrast 64 slice Siemens CT of bilateral temporal bones with $0.3 \mathrm{~mm}$ thin image reconstruction in coronal plane. FOV is $15.4 \mathrm{~cm}$.
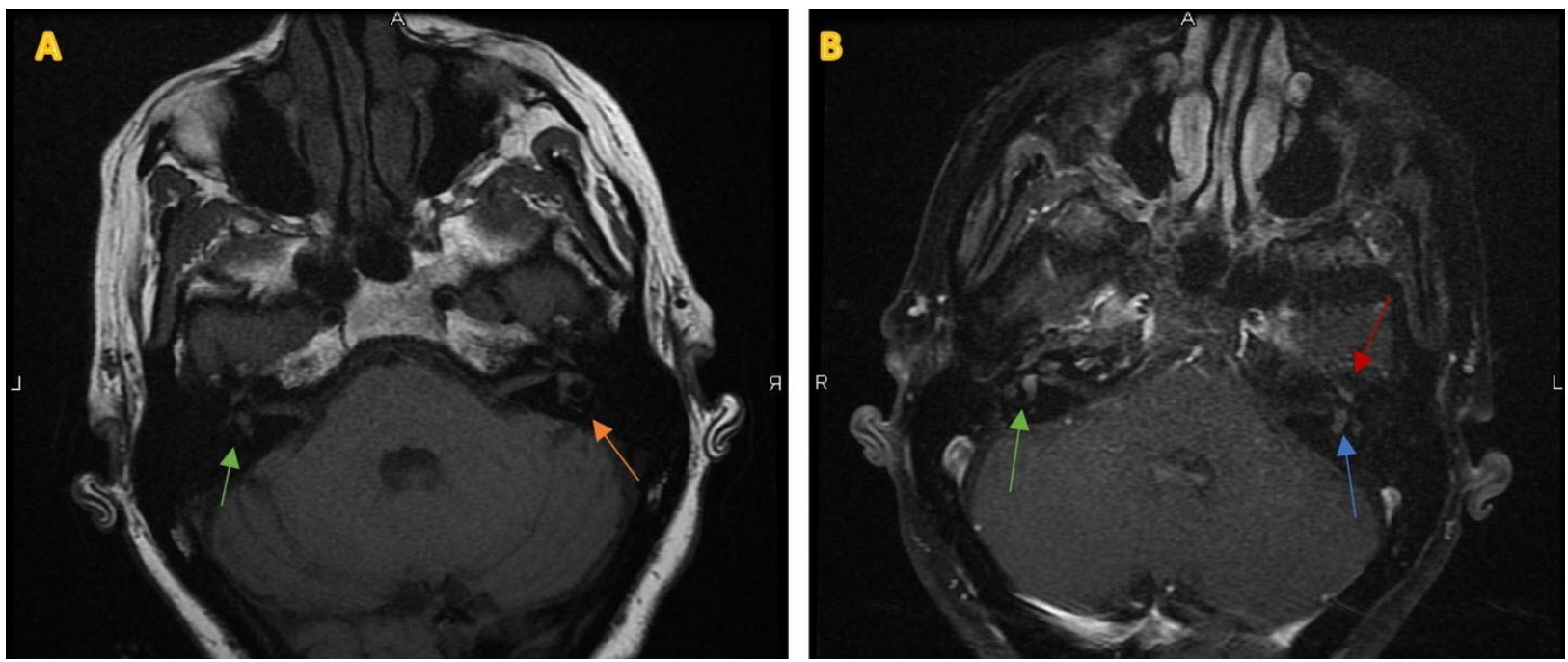

Figure 3: 67 year of female with a history of relapsing polychondritis in bilateral external ears and Diabetes mellites type-2 presented with progressive bilateral sensorineural hearing loss (left much worse than right) and positional vertigo[2,3,4,6].

Findings: Axial T1 pre contrast (A) demonstrates no obvious abnormality. Green arrow shows right membranous labyrinth and the orange arrow shows left membranous labyrinth. Axial T1 post contrast (B) demonstrates enhancement of the vestibules bilaterally, right vestibule (green arrow) greater than left vestibule (blue arrow), and in the right cochlea (red arrow).

Technique: Siemens 1.5 Tesla MRI scanner. Axial T1 pre contrast (A) and axial T1 post contrast (B). 3mm thick images through bilateral IACs. $20 \mathrm{cc}$ of IV Multihance was administered. Both sequences have FOV of $18 \mathrm{~cm}$. For T1, TR is 500 and TE is 16. For T1 post contrast, TR is 416 and TE is 22. 


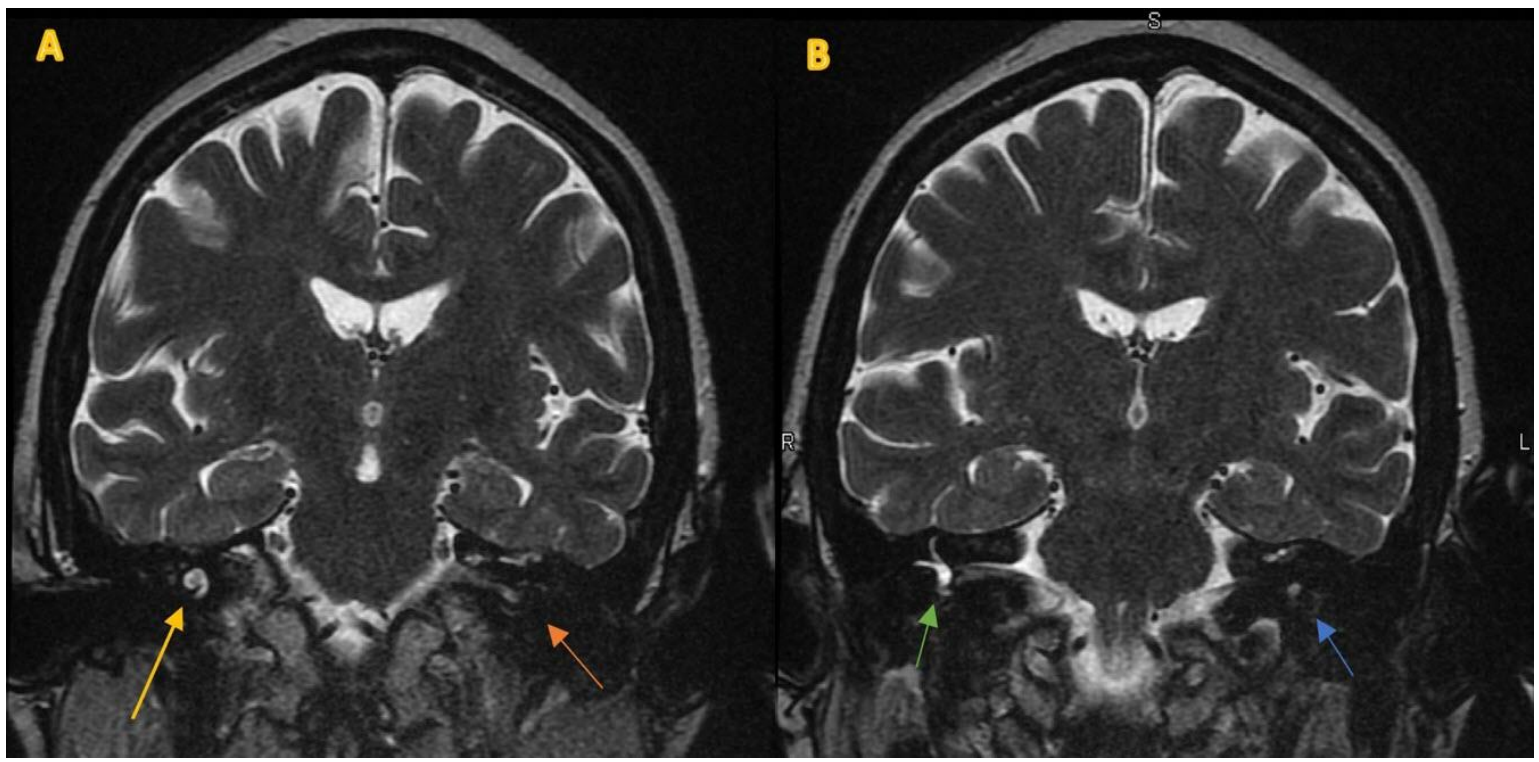

Figure 4: 67 year old female with a history of relapsing polychondritis in bilateral external ears and DM-2 presented with progressive bilateral sensorineural hearing loss (left much worse than right) and positional vertigo.

Findings: Coronal T2 (Fig. A and B) images through bilateral IACs. Fig A demonstrates low signal within the left cochlea (orange arrow) and fluid signal in the right cochlea (yellow arrow). Fig B demonstrates low signal within left vestibule (blue arrow) and fluid signal in the right vestibule (green arrow).

Technique: Siemens 1.5 Tesla MRI scanner. 3mm thick T2 coronal images (Fig. A and B) through bilateral IACs. FOV is $18 \mathrm{~cm}$. TR is 5600 and TE is 113.

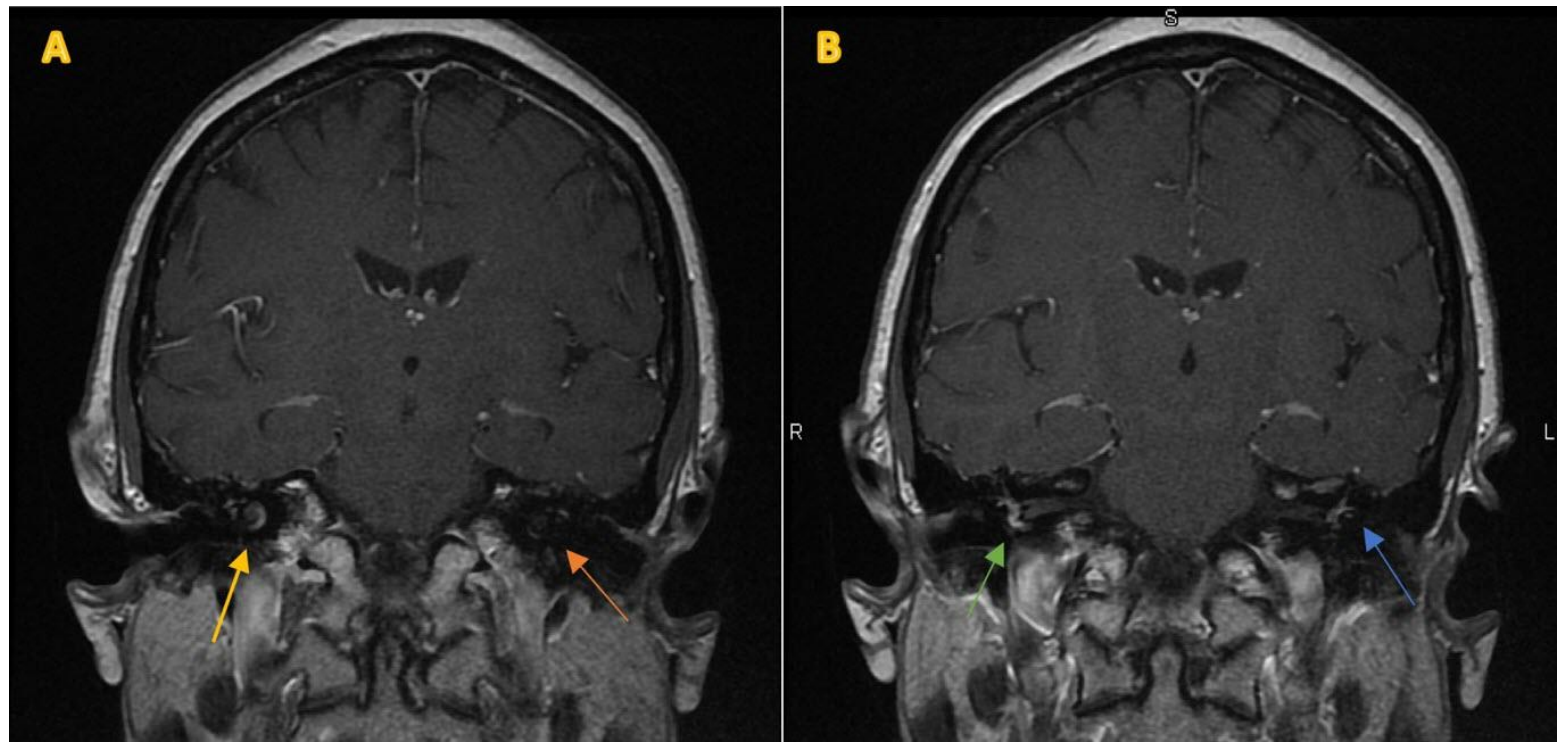

Figure 5: 67 year old female with a history of relapsing polychondritis in bilateral external ears and DM-2 presented with progressive bilateral sensorineural hearing loss (left much worse than right) and positional vertigo.

Findings: Coronal T1-weighted post contrast images (Fig. A and B) through bilateral IACs. Image A demonstrates enhancement within the right cochlea (yellow arrow) while the left cochlea (orange arrow) is not well seen. Image B demonstrates enhancement within bilateral vestibules and semicircular canals, severe on the right (green arrow) and moderate on the left (blue arrow).

Technique: Siemens 1.5 Tesla MRI scanner. 20 cc of IV Multihance was administered. Coronal T1 post contrast (Fig. A and B) $3 \mathrm{~mm}$ thick images through bilateral IACs. FOV is $18 \mathrm{~cm}$. TR is 583 and TE is 22. 


\begin{tabular}{|l|l|}
\hline Etiology & $\begin{array}{l}\text { More commonly infectious and inflammatory, and less commonly trauma, tumors, hemorrhage, } \\
\text { vascular obstruction of labyrinthine artery, surgical insult, and/or autoimmune inner ear disease. }\end{array}$ \\
\hline Incidence & $\begin{array}{l}\text { The reported incidence of hearing loss following meningitis ranges from 6-37\%, with an } \\
\text { estimated } 5 \% \text { suffering from profound deafness. As many as } 80 \% \text { of patients with profound } \\
\text { postmeningitic deafness have some degree of labyrinthine ossification. Complete ossification is } \\
\text { associated with a poor prognosis for residual hearing. }\end{array}$ \\
\hline Age predilection & It occurs in all age groups but is more common in 30 to 50-year old. \\
\hline Gender ratio & Females are 1.5 times more susceptible than males. \\
\hline Risk factors & Meningitis, Autoimmune disorders, Trauma, and/or surgical intervention. \\
\hline Treatments & $\begin{array}{l}\text { Cochlear implantation is an effective treatment option for sensorineural hearing loss. However, } \\
\text { ossification of the membranous labyrinth can make electrode implantation difficult, which in } \\
\text { turn may either complicate or preclude cochlear implantation, which can sometimes be overcome } \\
\text { by various complex surgical techniques. }\end{array}$ \\
\hline Prognosis & $\begin{array}{l}\text { Labyrinthitis Ossificans may either complicate or preclude cochlear implantation because } \\
\text { ossification limits the surgical placement of electrodes, and dense ossification may be a } \\
\text { contraindication for implant. }\end{array}$ \\
\hline Findings on imaging & $\begin{array}{l}\text { CT: ossification with sclerosis, irregularities or obliteration of the cochlea, semicircular canals, } \\
\text { or vestibule with different degrees of involvement. } \\
\text { MRI: Loss of normal fluid signal in the inner ear. Enhancement on MRI is seen in the early } \\
\text { acute/subacute stage when there is inflammation-related hypervascularity. }\end{array}$ \\
\hline
\end{tabular}

Table 1: Summary table for Labyrinthitis Ossificans

\begin{tabular}{|c|c|c|}
\hline & CT & MRI \\
\hline Labyrinthitis Ossificans & $\begin{array}{l}\text { May present with sclerosis, } \\
\text { irregularities or obliteration of the } \\
\text { cochlea; semicircular canals or } \\
\text { vestibule with different degrees of } \\
\text { involvement. }\end{array}$ & $\begin{array}{l}\text { T2 may show Loss of normal fluid signal in the } \\
\text { inner ear. T1 w/ contrast enhancement on MRI is } \\
\text { seen in the early acute/subacute stage when there } \\
\text { is inflammation-related hypervascularity. }\end{array}$ \\
\hline $\begin{array}{l}\text { Cochlear aplasia or } \\
\text { Labyrinthine aplasia or } \\
\text { absence of differentiated } \\
\text { inner ear structures. }\end{array}$ & $\begin{array}{l}\text { Hypoplasia of the petrous temporal } \\
\text { bone; hypoplastic and sclerotic petrous } \\
\text { apex may mimic LO. }\end{array}$ & $\begin{array}{l}\text { Hypoplasia of the petrous temporal bone; } \\
\text { hypoplastic and sclerotic petrous apex may mimic } \\
\text { LO. }\end{array}$ \\
\hline Otosclerosis & $\begin{array}{l}\text { Demineralized hypodense fenestral } \\
\text { spongiotic foci of otosclerosis are better } \\
\text { seen on axial HRCT. }\end{array}$ & $\begin{array}{l}\text { Has a limited role. In retrofenestral otosclerosis, } \\
\text { T1 with contrast enhancement may be } \\
\text { demonstrated. Increased T } 2 \text { signal may also be } \\
\text { present. }\end{array}$ \\
\hline
\end{tabular}

Table 2: Differential diagnosis table for Labyrinthitis Ossificans

\section{ABBREVIATIONS}

DM-2 = Diabetes mellites type 2

$\mathrm{FOV}=$ Field of View

HRCT $=$ High resolution Computed Tomography

IV = Intravenous

LO = Labyrinthitis ossificans

MRI = Magnetic Resonance Imaging

YOF $=$ year old female

\section{KEYWORDS}

Labyrinthitis; Labyrinthitis ossificans; Inner Ear; Hearing Loss; Vertigo

\section{Online access}

This publication is online available at: www.radiologycases.com/index.php/radiologycases/article/view/3706

\section{Peer discussion}

Discuss this manuscript in our protected discussion forum at: www.radiolopolis.com/forums/JRCR

\section{Interactivity}

This publication is available as an interactive article with scroll, window/level, magnify and more features. Available online at www.RadiologyCases.com

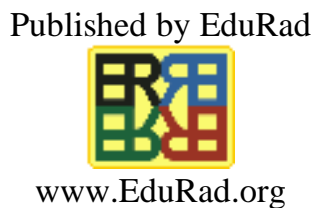

